Published by Al-Nahrain College of Medicine P-ISSN 1681-6579

E-ISSN 2224-4719

Email: iraqijms@colmed-alnahrain.edu.iq

http://www.colmed-alnahrain.edu.iq

http://www.iraqijms.net

Iraqi JMS 2021; Vol. 19(1)

\title{
Factors Related to Delayed Recovery After Anesthesia
}

\author{
Safa B. Karim PhD (Anesthesiology)
}

Dept. of Anesthesia Technology, Technical College of Health, Sulaimani Polytechnic University, Sulaimani, Iraq

\begin{abstract}
Background Delayed recovery from anesthesia is one of the important challenges that face anesthesiologist. The time of delayed recovery from anesthesia is related to anesthetic agent, patient, duration and type of surgery.

Objective To determine the factors from the patients and other things related to delayed recovery after giving anesthesia.

Methods A total of 286 patients were observed in Shar Medical Hospital and Cardiac Center in Sulaimani city, Iraq between November 2019 and March 2020. Post-operative evaluation and observation were collected for delayed and normal recovery after anesthesia. $P$ value less than 0.05 means significant relationship were obtained between variables.

Results From the 286 patients, 180 (62.94\%) were male, in which 66 of them were have delayed recovery and significant relation was found $p=0.005$. Most of the patients were $>50$ years-old $126(44.05 \%)$ and there was significant relation between age and delayed recovery of consciousness $p=0.01$. Delayed recovery was found among overweight more frequently than the underweight and normal weight (51 from 73 for overweight, 33 from 45 and 7 from 168, respectively). Also, significant relationship was found $\mathrm{p}=0.001$.

Conclusion Old age, male, obese patients and cigarette smokers, diabetes mellitus, cerebrovascular accident, history of myocardial infarction, hyperlipidemia, and neurological diseases are high risk factors for delayed recovery.

Keywords Anesthesia, delayed recovery, post-operative care, risk factors

Citation Karim SB. Factors related to delayed recovery after anesthesia. Iraqi JMS. 2021; 19(1): 39-48. doi: 10.22578/IJMS.19.1.6
\end{abstract}

List of abbreviations: $\mathrm{GA}=$ General anesthesia, $\mathrm{PaCO}_{2}=$ Partial pressure of carbon dioxide, SPSS $=$ Statistical Package for Social Sciences, $\chi^{2}=$ Chi-square

\section{Introduction}

A nesthesia is used to relieve pain during diagnostic procedures, and operative procedures. It is blocking the pathway that produces the pain from nerves in human body and leading to unconsciousness. It can be given to different parts of the body by various ways.

\section{Types of anesthesia}

There are three main types:
Regional anesthesia: Regional anesthesia is injection of the anesthetic agents to local area around the major nerves supplied to the area in the body this means that the person doesn't have to be sleep. It is divided in to three types according to injection; spinal, epidural and regional nerve block. The area of nerve blockage includes; thigh, ankle, forearm, hand, shoulder, and abdomen. Also, regional anesthesia uses to nerve locating device like nerve stimulator. It is producing numbness and tingling that leads to loss of movement and sensation in that part ${ }^{(1)}$. General anesthesia: general anesthesia means putting the patient unconscious by giving 
anesthetic agents such as drugs or gases, which are deep enough, the patient will not feel the pain. Also leads to changes in breathing and circulation. This needs consistently monitoring the patient and always manages the breathing and circulating systems. After operation the consciousness and sensation return back gradually, this means recovery ${ }^{(1)}$.

Local anesthesia: local anesthesia means putting anesthetic agents in to a small part of the body or near the surgical site. It causes numbness of this part which is injected, also used for short or simple operation such as dental and skin lesion or some injuries. In this type the patient is fully conscious. In spite of this, sedation also can be used to reduce the patient's consciousness and relieve the pain during the procedure that is unpleasant or uncomfortable such as in gastroscopy and colonoscopy ${ }^{(1)}$.

\section{Recovery could be divided into three phases after anesthesia}

Immediate recovery; it means return of consciousness, recovery of airway protective reflex and return of motor action which continues for short time. Intermediate recovery; it means regain little movement with coordination and feel of dizziness. This phase goes on for one hour after anesthesia, but the patient may be discharged and considered fit. Long term recovery; it means full recovery of the patient and mental function. This phase lasts for hours to seven days after anesthesia $(2,3)$.

Delayed recovery from anesthesia is one of the important challenges that face anesthesiologist. The time of delayed recovery from anesthesia is related to anesthetic agent, patient, duration and type of surgery. These factors and premedications are responsible for prolonged or delayed recovery. Non-pharmacological factors play important role in recovery, which may cause many serious sequels and metabolic disorders such as hyperglycemia, hypoglycemia and electrolyte disturbance, hypoxia, hypernatremia, hypertension, liver diseases, uremia and hypothyroidism. Early diagnosis of delayed recovery after operation should be done because delayed recovery may be due to hypoxia, hemorrhage, thrombosis and embolism in the brain. Emergency management should be used to maintain airway, breathing and circulation. On the other hand, the risk factors and causes, of delayed recovery depend on the previous experience and information from the patient from previous operation (4).

Recovery from anesthesia especially, intravenous opioids and hypnotics are more difficult and extend more than recovery from respiratory inhalation drugs. After operation the patients should stay in operating room till they have stable airway and circulating parameters. More frequent post-operative respiratory and circulation systems complications occur when the patients leave the recovery room early ${ }^{(2)}$.

Delayed recovery after general anesthesia is characterized by continuous somnolence; it means that the patients cannot be triggered. But patients how don't have any medical related condition for delayed recovery could be due to undiagnosed conditions. There are several risk factors responsible for delay recovery (Table 1) (4).

Development of successful implementation and management of delayed recovery after surgery or post-operatively occur by a process that makes a climate for change to delegate and promote the successful implementation and management ${ }^{(5)}$.

Management, team training and safety materials are useful considerations to change this magnitude. Creating a specialty may progress recovery pathway this process done throughout learning from other expert anesthetists or by correlating collaborative network of colleagues, also by continued review of the articles related to the anesthesia especially, recovery from anesthesia ${ }^{(6,7)}$. 
Table 1. Factors responsible for delayed recovery ${ }^{(4)}$

\begin{tabular}{cccc}
\hline Patient factors & Drug factors & Surgical factors & Metabolic factors \\
\hline Gender & Dosage & Duration of surgery & Hyper/hypoglycemia \\
\hline Old age & Metabolism & $\begin{array}{c}\text { Type of muscle } \\
\text { relaxant uses }\end{array}$ & Hyper/hypernatremia \\
\hline $\begin{array}{c}\text { Variation of gene } \\
\text { system disorders }\end{array}$ & $\begin{array}{c}\text { Time of } \\
\text { administration }\end{array}$ & Hypotension & Hypothyroidism \\
\hline Co-morbidity & Drug interaction & Hypoxia & Hyperthermia \\
\hline Body habits & Fluid disturbance & $\begin{array}{c}\text { Neuro and cardiac } \\
\text { surgery }\end{array}$ & Acidosis \\
\hline Cognitive dysfunction & $\begin{array}{c}\text { Anesthetic agent } \\
\text { toxicity }\end{array}$ & $\begin{array}{c}\text { Regional techniques } \\
\text { with sedation }\end{array}$ & $\begin{array}{c}\text { Central anticholinergic } \\
\text { problems }\end{array}$ \\
\hline Seizures & $\begin{array}{r}\text { Gas solubility in the } \\
\text { body }\end{array}$ & $\begin{array}{c}\text { Stimulation of pain } \\
\text { ftim }\end{array}$ & $\begin{array}{c}\text { Renal or hepatic } \\
\text { failure }\end{array}$ \\
\hline
\end{tabular}

Any patient before anesthesia will need preoperative evaluation to identify health conditions that affect management during operation or post-operatively especially recovery after general anesthesia ${ }^{(2)}$. It is known that some of the physical and psychological factors may affect delayed recovery from surgery and anesthesia ${ }^{(8)}$. Pre-operative anxiety for most patients was shown and associated with delayed recovery ${ }^{(9)}$. Premedication drugs to relieve anxiety should be administrated which is improving, helping and minimizing post-operative complication and delayed recovery ${ }^{(10)}$.

On the other hand, surgical stress affects catabolic state that raises cardiac demand for oxygen, raises insulin resistance, change profile of coagulation and modify gastrointestinal and pulmonary functions ${ }^{(11)}$. This process leads to dysfunction of most of the organs in the body and increase morbidity which leads to delayed recovery ${ }^{(12)}$. Thromboembolism, nosocomial infection and long-term dysfunction of life may result from delayed recovery, also delayed recovery increases cost of health care which is another major problem ${ }^{(13)}$.

Post-operative care has essential criteria for the patient's evaluation, assessment, documentation and monitoring especially during recovery periods. Recovery status started when the patients were assessed, and evaluated following return of consciousness and system functions comes from additional guidance review from American Association of Nurse Anesthesiology (14). Also, the patient will return to the normal life activity few hours after operation ${ }^{(15,16)}$. The recovery staff should asses the patient's condition and must be satisfied that the patient recovered safely from anesthesia and all of the vital signs were normal such as pulse rate and blood pressure after that the patient can go to the ward ${ }^{(17)}$. There are many previous studies revealed that many risk factors lead to delayed recovery of the patients after anesthesia.

\section{Patients factors}

Age; geriatric patients or elderly patients are more sensitive to anesthetic drugs. They will return their consciousness slowly because of decline in their central nervous system function. Previous study showed that request for opioids decreased by more than $50 \%$ in elderly patients. The effect of midazolam in old patents can depress mental function and lead to delayed recovery and delayed hospital discharge ${ }^{(17,18)}$. 
But another study revealed that pediatric age also reported delayed recovery because of slow drug metabolism and heat loss resulting in hypothermia. Genetic factors related to the patient affect the response and disposition of the drugs especially, anesthetic drugs, and play important roles in drug adverse effect determination (4). A study by Apfelbaum et al. revealed that male have more delayed recovery than female 1.4 times ${ }^{(19)}$.

Previous study shown that obese patients more likely to get delayed recovery because of the increased fat, which require high drug concentration in plasma than a normal body weight patient (17).

Chronic or previous cardiac and respiratory diseases require more specific pre- and postoperative care and reducing anesthetic drug doses to avoid complications and delayed recovery. Previous study demonstrated that lung diseases, congestive heart failure and renal failure were the most risk conditions which lead to delayed recovery from anesthesia (20). Also, hypothyroid patients have 1-10-times delayed recovery than the normal persons ${ }^{(21)}$.

Psychological and central nervous system diseases may cause post-operative somnolence. Patient with Parkinson's disease is more likely to get delayed recovery because of low brain dopamine concentration (18). A study by Sahoo et al. revealed that patients with long term seizure have delayed recovery more than 3.5 hours when medicated by Rocuronium and Phenytoin (22). Pain after operation plays important role to speed up recovery. Also, the recovery becomes delayed when analgesics given to the patients ${ }^{(20)}$.

\section{Drug factors}

Drug administration commonly can cause delayed recovery after over dose of anesthetic agents ${ }^{(23)}$. Drug dosage has different effects on the same patient, a high drug dose in general anesthesia can cause delayed recovery ${ }^{(24)}$.

Previous study revealed that injection of benzodiazepines and opioids, also nonanesthetic drugs such as antihypertensive, antihistamines, some antibiotics, immunosuppressant's, and alcohol cause depression of central nervous system which led to delayed recovery ${ }^{(25)}$.

Drug interaction is another factor can cause delayed recovery resulting in hypo/hypertension and coma after operation. Many drugs interact with the neuromuscular or anesthetic agents like diuretics, oral contraceptive pills, aminoglycosides, which cause prolonged neuromuscular junction block (26).

\section{Duration of anesthetic used}

Anesthetic drug administration techniques responsible for the duration of awareness after anesthesia (27). A study by Garg et al. revealed that delayed recovery after long time laparoscopic procedure for hernia repair by general anesthesia occurs ${ }^{(28)}$. Also, repeated administration of anesthetic agents for long term surgery is another cause for delayed recovery (29). Early respiratory depression caused by Neuraxial opioids leads to delayed recovery. Previous study shown that benzodiazepines combined with opioids leads to respiratory depression and causes coma that prolong recovery (30). Various intravenous anesthetic agents determine the time of recovery, previous study demonstrated that duration of consciousness depends on the agents were given, Propofol has a short half-life about 10-70 minutes which is metabolized by liver has fast recovery ${ }^{(31)}$.

\section{Metabolic causes}

Hypo and hyperglycemia play an important role in delayed recovery, diabetic ketoacidosis may

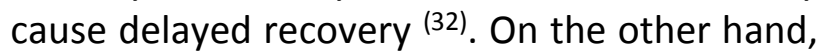
hypoglycemia was another factor results due to prolonged fasting before operation which leads to delayed recovery ${ }^{(21)}$.

\section{Imbalance of electrolytes}

Electrolytes change and acid-base disturbance in pre-operative period were the most 
important factors, which lead to delayed recovery after anesthesia. A study by Razvi et al. shown that sodium loss by the kidneys resulting in hypernatremia can cause delayed recovery (33).

In old aged patients, hypothermia, if suspected temperature less than $33^{\circ} \mathrm{C}$ with the anesthetic drugs may reduce minimum alveolar concentration value and lead to decreased drug metabolism and delayed recovery occurs (21). But another study revealed that temperature more than $40{ }^{\circ} \mathrm{C}$ can cause loss of consciousness, which leads to delayed recovery (4). Post-operative respiratory dysfunction leads to muscular dysfunction and hypoxia resulting in hypoxemia and affects cerebral functions and may cause damage of the cerebral cells followed by delayed recovery when $\mathrm{PaCO}^{2}$ raised above 90-120 mm Hg ${ }^{(29)}$. Complications of the central nervous system or neurological disorders during operation such as hemorrhage, hematoma and cerebral infarction also, long period of hypoxemia may cause cerebral dysfunction and lead to delayed recovery ${ }^{(28)}$. During improperly sitting position of patient hypo perfusion can occur and leads to obstruction of blood flow in the carotid and vertebral circulation in the neck of the patient resulting in hypoxia and leads to delayed recovery (17). Adequate analgesia was necessary for post-operative period to return the patient to normal activities; the aim of this procedure is to reduce pain. A study by Ramsay conducted that post-operative analgesia leads to low incidence of complications and decreases the delayed recovery status (34).

The aim of this study is to determine the factors from the patients and other things related to delayed recovery after giving anesthesia. Reducing those factors plays important role to enhance patient quality life.

\section{Methods}

During the study period, 286 patients were observed in Shar Medical Hospital \& Cardiac Center in Sulaimani city between November 2019 and March 2020. The study population includes those patients undergoing admitted to the hospital for Surgery. A structured data sheet was used to collect the information's from the patients. Demographic characteristics of the patients, history of previous diseases, medications and type of surgery were taken. Anesthesia drugs include: Propofol, Benzodiazepines, Opioids (Fentanyl or Sufentanil), Atracurium, Thiopental and Scolin. Post-operative evaluation and observation were collected for delayed and normal recovery after anesthesia. Data analyzed by SPSS (Statistical Package for Social Sciences) software version 22. Frequencies, percentage, mean were used for statistical correlations. Chi-square $(\chi 2)$ test was used for significant association between the variables. P-value less than 0.05 means significant relationship were obtained between variables.

\section{Results}

The present study includes 286 patients undergoing surgery, 195 (68.91\%) of them were with normal recovery after anesthesia and 91 (31.81\%) were with delayed recovery after anesthesia (Table 2).

Table 2. Patients distribution according delayed recovery

\begin{tabular}{ccc}
\hline Recovery & No. & $\%$ \\
\hline Delayed recovery & 91 & 31.81 \\
Normal recovery & 195 & 68.19 \\
\hline Total & 286 & 100 \\
\hline
\end{tabular}

From the 286 patients, 180 (62.94\%) were males, in which 66 of them were have delayed recovery and significant relation was found $p=0.005$. Patients from rural area are more 
frequent 174 (60.84\%). The mean age was 42.8 \pm 21.6 years started from 6 months to 91 yearsold. Most of the patients were $>50$ years-old 126 (44.05\%) followed by $<18$ years old and there was significant relation between age and delayed recovery of consciousness $p=0.01$. delayed recovery was found among overweight more frequently than the underweight and normal weight (51 from 73 for overweight, 33 from 45 and 7 from 168, respectively). Also, significant relationship was found $p=0.001$. From 86 smoker patients 62 of them have delayed recovery from consciousness and the association between smoker and recovery is statistically significant $p=0.003$. Also, for alcoholic patients the significant relationship was found $p=0.03$ (Table 3 ).

Table 3. Patients characteristics in relation to recovery

\begin{tabular}{|c|c|c|c|c|}
\hline \multicolumn{2}{|c|}{ Variable } & \multirow{2}{*}{$\begin{array}{c}\text { No. (\%) } \\
180(62.94)\end{array}$} & \multirow{3}{*}{$\begin{array}{c}\text { Delayed recovery No. } \\
66 \\
25\end{array}$} & \multirow{3}{*}{$\begin{array}{c}\text { p-value } \\
0.005\end{array}$} \\
\hline \multirow{2}{*}{ Gender } & Male & & & \\
\hline & Female & $106(37.06)$ & & \\
\hline \multirow{2}{*}{ Residency } & Urban & $112(39.16)$ & 36 & \multirow{2}{*}{0.6} \\
\hline & Rural & $174(60.84)$ & 55 & \\
\hline \multirow{3}{*}{ Age group } & $<18$ & $104(36.37)$ & 27 & \multirow{3}{*}{0.01} \\
\hline & $18-50$ & 56 (19.58) & 10 & \\
\hline & $>50$ & $126(44.05)$ & 54 & \\
\hline \multirow{3}{*}{ Body weight } & Underweight & 45 (15.74) & 33 & \multirow{3}{*}{0.001} \\
\hline & Normal & $168(58.74)$ & 7 & \\
\hline & Overweight & $73(25.52)$ & 51 & \\
\hline \multirow{2}{*}{ Smoker } & Yes & 86 (30.07) & 62 & \multirow{2}{*}{0.003} \\
\hline & No & $200(69.93)$ & 29 & \\
\hline \multirow{2}{*}{ Alcohol use } & Yes & $31(10.84)$ & 22 & \multirow{2}{*}{0.03} \\
\hline & No & $255(89.16)$ & 69 & \\
\hline \multicolumn{2}{|c|}{ Total } & $286(100)$ & 91 & \\
\hline
\end{tabular}

Table 4 shows diseases in relation to delayed recovery from anesthesia. In this table there were significant association between recovery of consciousness after surgery / anesthesia and diabetes mellitus $(p=0.001)$, cerebrovascular accident $(p=0.03)$, history of myocardial infarction $(p=0.002)$, hyperlipidemia $(p=0.003)$, neurological diseases $(p=0.001)$, hypothyroidism $(p=0.001)$, history of previous surgery $(p=0.05)$ and mental disorders $(p=0.001)$. But for hypertension, renal diseases, liver diseases and hyperthyroidism the significant association was not found $(p=0.2$, $p=82, p=0.16$ and $p=0.9$ respectively).

From 286 patients, 162 (56.65\%) of them have anxiety before operation, in which 45 of them suffered from delayed recovery. 171 (39.21\%) of them with short time fasting; significant relationship was not found between anxiety and short time fasting with delayed recovery $(p=0.86$ and 0.64$)$. But the majority of patients who used analgesia during surgery 195 (68.19\%) have significant association with delayed recovery $(p=0.03)$ (Table 5$)$. 
Table 4. Distribution diseases related to delayed recovery from anesthesia

\begin{tabular}{|c|c|c|c|c|}
\hline Diseases & & No. (\%) & Delayed recovery No. (\%) & p-value \\
\hline \multirow{2}{*}{ Diabetes mellitus } & Yes & $62(21.68)$ & 62 & \multirow{2}{*}{0.001} \\
\hline & No & $244(78.32)$ & 29 & \\
\hline \multirow{2}{*}{ Hypertension } & Yes & $71(24.83)$ & 44 & \multirow{2}{*}{0.2} \\
\hline & No & $215(75.17)$ & 47 & \\
\hline \multirow{2}{*}{ Cerebrovascular accident } & Yes & $12(4.2)$ & 8 & \multirow{2}{*}{0.03} \\
\hline & No & $274(95.8)$ & 83 & \\
\hline \multirow{2}{*}{$\begin{array}{l}\text { History of myocardial } \\
\text { infarction }\end{array}$} & Yes & $16(5.6)$ & 12 & \multirow{2}{*}{0.002} \\
\hline & No & $270(94.4)$ & 79 & \\
\hline \multirow{2}{*}{ Hyperlipidemia } & Yes & $122(42.66)$ & 86 & \multirow{2}{*}{0.003} \\
\hline & No & $164(57.34)$ & 5 & \\
\hline \multirow{2}{*}{ Neurological diseases } & Yes & $14(4.9)$ & 9 & \multirow{2}{*}{0.001} \\
\hline & No & $272(95.1)$ & 82 & \\
\hline \multirow{2}{*}{ Renal diseases } & Yes & 48 (16.79) & 12 & \multirow{2}{*}{0.82} \\
\hline & No & $238(83.21)$ & 49 & \\
\hline \multirow{2}{*}{ Liver diseases } & Yes & $9(3.15)$ & 2 & \multirow{2}{*}{0.16} \\
\hline & No & $277(96.85)$ & 89 & \\
\hline \multirow{2}{*}{ Hypothyroidism } & Yes & $49(17.14)$ & 33 & \multirow{2}{*}{0.001} \\
\hline & No & $237(82.86)$ & 58 & \\
\hline \multirow{2}{*}{ Hyperthyroidism } & Yes & $14(4.9)$ & 2 & \multirow{2}{*}{0.9} \\
\hline & No & $272(95.1)$ & 89 & \\
\hline \multirow{2}{*}{ History of previous surgery } & Yes & $65(22.73)$ & 24 & \multirow{2}{*}{0.05} \\
\hline & No & $221(77.27)$ & 67 & \\
\hline \multirow{2}{*}{ Mental disorders } & Yes & $6(2.1)$ & 4 & \multirow{2}{*}{0.001} \\
\hline & No & 280 (97.9) & 87 & \\
\hline Total & & $286(100)$ & 91 & \\
\hline
\end{tabular}

Table 5. Distribution of risk factors

\begin{tabular}{ccccc}
\hline \multicolumn{1}{c}{ Risk factors } & & No. (\%) & Delayed recovery No. (\%) & p-value \\
\hline \multirow{2}{*}{ Anxiety } & Yes & $162(56.65)$ & 45 & \multirow{2}{*}{0.86} \\
\hline \multirow{2}{*}{ Short time fasting } & No & $124(43.35)$ & 45 & \multirow{2}{*}{0.64} \\
\hline \multirow{2}{*}{ Analgesia uses during surgery } & Yes & $115(40.21)$ & 72 & \multirow{2}{*}{0.03} \\
\hline Notal & No & $171(39.21)$ & 72 & \\
\hline & No & $91(31.81)$ & 19 & \\
\hline
\end{tabular}

Table 6 shows history of drug administration in relation to recovery from anesthesia. The association between drug administration and delayed recovery from anesthesia were found for Aspirin/Clopidogrel, Beta blockers, Diuretics,
Insulin or other ant diabetic drugs, Calcium channel blockers, Angiotensin and Nonsteroidal anti-inflammatory drugs $(p=0.04$, $0.001,0.02,0.001,0.001,0.02$ and 0.05 respectively). 
Table 6. History of drug administration in relation to recovery

\begin{tabular}{lcccc}
\hline Drugs & No. & $\begin{array}{c}\text { Delayed } \\
\text { recovery }\end{array}$ & $\begin{array}{c}\text { Normal } \\
\text { recovery }\end{array}$ & $\begin{array}{c}\text { p- } \\
\text { value }\end{array}$ \\
\hline Aspirin/clopidogrel & 112 & 69 & 22 & 0.04 \\
\hline Beta blockers & 132 & 87 & 4 & 0.001 \\
\hline Diuretics & 86 & 65 & 26 & 0.02 \\
\hline Insulin and anti-diabetic drugs & 92 & 81 & 10 & 0.001 \\
\hline Calcium channel blockers & 82 & 12 & 79 & 0.001 \\
\hline Angiotensin & 46 & 5 & 86 & 0.02 \\
\hline $\begin{array}{l}\text { Non-steroidal anti-inflammatory } \\
\text { drugs }\end{array}$ & 97 & 66 & 25 & 0.05 \\
\hline
\end{tabular}

\section{Discussion}

In our study we found that male, old and pediatric age groups, overweight patients, cigarette smokers and alcoholics were high risk factors for delayed recovery. Similar result was found in the previous study which is conducted by Faritous et al. (35). Previous study demonstrated that anesthetic drugs are removed or metabolized by $50 \%$ in old age patients because of decreasing plasma protein binding capacity resulting in increasing level of free plasma concentration of anesthetic drugs (17). Regarding gender, female have lower sensitivity to the hypnotic effects of drugs especially, anesthetic drugs because of this, female quick recover from anesthesia (36). Also, overweight patients have increased amount of fat in their bodies, who require high doses of drugs to get acting in plasma protein than the normal body weight persons (37).

In the current study, significant association between recovery of consciousness after surgery/anesthesia and diabetes mellitus, cerebrovascular accident, history of myocardial infarction, hyperlipidemia, neurological diseases, hypothyroidism, history of previous surgery and mental disorders were shown. The previous study is nearly consistent with the current study which is reported that cerebrovascular accidents and neurological disorders are related to the delayed recovery (38).

In the current study, significant association was found between delayed recovery and previous drug usage by the patients. When these drugs (antihypertensive, antidiuretics, etc.) are used for prolonged periods especially, in elderly people, will interact with anesthetic drugs and this leads to delayed recovery because the metabolism of the anesthetic drugs will be delayed. This interaction between these drugs will cause toxic effects on the circulatory, respiratory and nervous system in the body (22). In the current study, patients with diabetes mellitus are more likely to have delayed recovery after anesthesia. Previous study agreed with this study and mentioned that high level of blood glucose causes osmotic diuresis and dehydration in diabetic patients. The dehydration can cause drowsiness because of acidosis resulting in delayed recovery from consciousness ${ }^{(27)}$.

The study shown that use of analgesics during operation was the common reason for delayed recovery. A study by Rastogi et al. revealed that interaction between analgesics and opioids was the commonest reason which can cause delayed recovery ${ }^{(39)}$.

Regarding, respiratory system, we found that patients with respiratory diseases have significant relations with delayed recovery. Similar result was found in the previous study which revealed that pulmonary diseases result in hypoxemia and will decrease cerebral function and causing cell damage (29).

Smoking may cause hypoxia in the cerebrum and destroy the function of the brain, which cause cerebral cell damage due to free radicals' accumulation and production of lactic acid. Also, smokers need more doses of muscle 
relaxants during operation to maintain neuromuscular blockade, which will lead to delayed recovery ${ }^{(40)}$.

In conclusion, old age, male, obese patients and cigarette smokers were high risk factors for delayed recovery. Diabetes mellitus, cerebrovascular accident, history of myocardial infarction, hyperlipidemia, neurological diseases, history of previous surgery and mental disorders also were common risk factors for delayed recovery from anesthesia. We recommend that pre and postoperative patient care can ensure the patient safety.

\section{Acknowledgement}

Authors like to acknowledge all the staff in Shar Hospital and Cardiac Center in Sulaimani City.

\section{Conflict of interest}

Author declares no conflict of interest.

\section{Funding}

Self-funding.

\section{References}

1. Mahoney PF, Wood P, Jeyanathan J, et al. Anaesthesia Handbook. International Committee of the Red Cross. 2017.

2. Parr SM, Robinson BJ, Glover PW, et al. Level of consciousness on arrival in the recovery room and the development of early respiratory morbidity. Anaesth Intensive Care. 1991; 19(3): 369-72. doi: 10.1177/0310057X9101900310.

3. Steward DJ, Volgyesi G. Stabilometry. a new tool for the measurement of recovery following general anaesthesia for out-patients. Can Anaesth Soc J. 1978; 25(1): 4-6. doi: 10.1007/BF03006775.

4. Misal US, Joshi SA, Shaikh MM. Delayed recovery from anesthesia: A postgraduate educational review. Anesth Essays Res. 2016; 10(2): 164-72. doi: 10.4103/0259-1162.165506.

5. Pearsall EA, Meghji Z, Pitzul KB, et al. A qualitative study to understand the barriers and enablers in implementing an enhanced recovery after surgery program. Ann Surg. 2015; 261(1): 92-6. doi: 10.1097/SLA.0000000000000604.

6. Nancarrow SA, Booth A, Ariss S, et al. Ten principles of good interdisciplinary team work. Hum Resour Health. 2013; 11: 19. doi: 10.1186/1478-4491-11-19.

7. McLeod RS, Aarts MA, Chung F, et al. Development of an enhanced recovery after surgery guideline and implementation strategy based on the knowledge-toaction cycle. Ann Surg. 2015; 262(6): 1016-25. doi: $10.1097 /$ SLA.0000000000001067.
8. Liu R, Barry JE, Weinman J. Effects of background stress and anxiety on postoperative recovery. Anaesthesia. 1994; 49(5): 382-6. doi: 10.1111/j.13652044.1994.tb03467.x.

9. Parris $W C$, Matt $D$, Jamison $R N$, et al. Anxiety and postoperative recovery in ambulatory surgery patients. Anesth Prog. 1988; 35(2): 61-4.

10. Weinman J, Johnston M. Stressful medical procedures: an analysis of the effects of psychological interventions and of the stressfulness of the procedures. In: Maes S. Defares P. Sarason I. et al. Topics in first international expert conference on health psychology. Chichester: Wiley; 1988.

11. Kehlet $H$, Wilmore DW. Evidence-based surgical care and the evolution of fast-track surgery. Ann Surg. 2008; 248(2): 189-98. doi: 10.1097/SLA.0b013e31817f2c1a.

12. Wilmore DW. From cuthbertson to fast-track surgery: 70 years of progress in reducing stress in surgical patients. Ann Surg. 2002; 236(5): 643-8. doi: 10.1097/00000658-200211000-00015.

13. Sharma A, Sharp DM, Walker LG, et al. Predictors of early postoperative quality of life after elective resection for colorectal cancer. Ann Surg Oncol. 2007; 14(12): 3435-42. doi: 10.1245/s10434-007-9554-x.

14. American Association of Nurse Anesthetists. Postanesthesia care standards for the certified registered nurse anesthetist. 2013.

15. Kitching A, O'Neil S. Fast-track surgery and anesthesia. Contin Educ Anaesth Crit Care Pain. 2009; 9: 39-43.

16. Miller ET, Gan TJ, Thacker JK. Enhanced recovery pathways for major abdominal surgery. Anesthesiology News. 2014.

17. Frost EA. Differential diagnosis of delayed awakening from general anesthesia: a review. Middle East J Anaesthesiol. 2014; 22(6): 537-48.

18. Bowie MW, Slattum PW. Pharmacodynamics in older adults: a review. Am J Geriatr Pharmacother. 2007; 5(3): 263-303. doi: 10.1016/j.amjopharm.2007.10.001.

19. Apfelbaum JL, Grasela TH, Hug CC Jr, et al. The initial clinical experience of 1819 physicians in maintaining anesthesia with propofol: characteristics associated with prolonged time to awakening. Anesth Analg. 1993; 77(4 Suppl): S10-4.

20. Aitkenhead AR, Rowbotham DJ, Smith G. Textbook of Anaesthesia. $4^{\text {th }}$ ed. London, England: Churchill Livingston; 2001.

21. Denlinger JK. Prolonged emergence and failure to regain consciousness. Complications in Anesthesiology. Philadelphia, Unites States of America: JB Lippincott; 1983. p. 368-78.

22. Sahoo S, Kaur M, Sawhney C, et al. An unusual cause of delayed recovery from anesthesia. J Anaesthesiol Clin Pharmacol. 2012; 28(3): 415-6. doi: 10.4103/0970-9185.98380.

23. Shaikh SI, Lakshmi RR. Delayed awakening after anaesthesia - A challenge for an anaesthesiologist. Int J Biomed Adv Res. 2014; 5: 252-4. 
24. Nichoiau D. Postanesthesia recovery. Basics of Anesthesia. $5^{\text {th }}$ ed. Philadelphia, United States of America: Churchill Livingston; 2007. p. 577-8.

25. Radhakrishnan $R$, Jesudasan $S$, Jacob R. Delayed awakening or emergence from anaesthesia. Update Anaesth. 2001; 13: 4-6.

26. Sinclair RCF, Faleiro RJ. Delayed recovery of consciousness after anaesthesia. Contin Educ Anaesth Crit Care Pain. 2006; 6: 124-8. doi:10.1093/bjaceaccp/mkl020.

27. Pavlin DJ, Rapp SE, Polissar NL, et al. Factors affecting discharge time in adult outpatients. Anesth Analg. 1998; 87(4): 816-26. doi: 10.1097/00000539$199810000-00014$.

28. Garg R, Punj J, Pandey R, et al. Delayed recovery due to exaggerated acid, base and electrolyte imbalance in prolonged laparoscopic repair of diaphragmatic hernia. Saudi J Anaesth. 2011; 5(1): 79-81. doi: 10.4103/1658-354X.76477.

29. Campbell CE. Delayed awakening or delirium. Decision making in anesthesia. $4^{\text {th }}$ ed. Philadelphia, United States of America: Mosby; 2007. p. 582-5.

30. Stoelting RK, Hiller SC. Pharmacology and physiology in anesthetic practice. $4^{\text {th }}$ ed. United States of America: Lippincott Williams and Wilkins; 2006. p. 140-54.

31. Sarangi S. Delayed awakening from anaesthesia. Internet J Anesthesiol. 2008; 19(1).

32. Kong $X, M a H$, Deng $H$, et al. Delayed recovery from anesthesia following suboccipital craniotomy: A case report and literature review. J Surg Anesth. 2017; 1: 104.

33. Razvi M, Bameshki A, Gilani MT. Delayed awakening from anesthesia following electrolyte and acid-base disorders, two cases. J Patient Saf Qual Improv. 2014; 2(1): 65-8. doi: 10.22038/PSJ.2014.2097.

34. Ramsay MA. Acute postoperative pain management. Proc (Bayl Univ Med Cent). 2000; 13(3): 244-7. doi: 10.1080/08998280.2000.11927683.

35. Faritous Z, Madadipoor S, Ghadrdoost B, et al. Factors related to prolonged recovery of consciousness following cardiac surgery. Iran Heart J. 2017; 18(4): 427.

36. Buchanan FF, Myles PS, Leslie K, et al. Gender and recovery after general anesthesia combined with neuromuscular blocking drugs. Anesth Analg. 2006; 102(1): 291-7. doi: 10.1213/01.ANE.0000181321.55422.C6.

37. Tsai HJ, Chen CC, Chang KY. Patients and surgeryrelated factors that affect time to recovery of consciousness in adult patients undergoing elective cardiac surgery. J Chin Med Assoc. 2011; 74(8): 345-9. doi: 10.1016/j.jcma.2011.06.009.

38. Baranowska K, Juszczyk G, Dmitruk I, et al. Risk factors of neurological complications in cardiac surgery. Kardiol Pol. 2012; 70(8): 811-8.

39. Rastogi R, Swarm RA, Patel TA. Case scenario: opioid association with serotonin syndrome: implications to the practitioners. Anesthesiology. 2011; 115(6): 12918. doi: 10.1097/ALN.0b013e31823940c0.

40. Rodrigo C. The Effects of Cigarette Smoking on Anesthesia. Anesth Prog. 2000; 47(4): 143-50.
E-mail: Safa.bakr@spu.edu.iq
Received Dec. 13 2020
Accepted Jan. 21 2020 